\title{
Iraq: children's and adolescents' mental health under conditions of continuous turmoil
}

\author{
AbdulKareem AlObaidi
}

Visiting scholar at the Institute for International Education (IIE), New York, USA, email kareemobaidi@gmail.com

\begin{abstract}
hildren and adolescents constitute half of Iraq's population of over 30 million. Mental health problems experienced by Iraqi children and adolescents are a hidden problem. Many factors contribute to the mental health problems of young Iraqis, including being victims and witnesses to violence, seeing family members become victims, being displaced from their homes, and experiencing the instability that still plagues their nation. Iraqis have experienced severe deprivation caused by many years of war, economic embargoes and civil unrest. Violence, poverty and the failure of the education and health systems have severely undermined the well-being of Iraqis, especially children (AlObaidi et al, 2009).
\end{abstract}

Child and adolescent mental health is a major concern, especially as it is increasingly recognised as a key influence on and predictor of problems in adulthood. Current events in Iraq have raised concerns about the consequences of trauma and stress on the mental health of the country's youth. Addressing the mental health needs of children and adolescents is critical to the success of relief efforts and requires effective, coordinated interventions.

\section{Shortage of resources}

Interest in the mental health of children in Iraq is a relatively recent development. Biomedical care for adults with mental illnesses began about 60 years ago with the formation of separate psychiatric hospitals in the capital city (Baghdad), and became part of general hospital care across Iraq just three decades ago.

In Iraq, child and adolescent mental health services (CAMHS) are commonly provided in out-patient mental healthcare facilities for the general population. Psychotropic medications are virtually the exclusive mode of therapeutic treatment. A small CAMHS clinic with very limited resources was launched at the Central Child Hospital in Baghdad in 2003. In addition, a number of institutes for children with special needs and residential homes for orphans are run by governmental and non-governmental agencies. However, a lack of resources and staff training may undermine the provision of services by these institutions.

Multidisciplinary work and behavioural, play and other forms of psychotherapy are not part of standard practice. School-based CAMHS are not available. A small team of psychologists and social workers serve in the Iraqi juvenile justice system, but they have no specialist training in the treatment and rehabilitation of youth offenders.

The current instability and violence prevalent in Iraq limit the work of national and international non-governmental organisations (INGOs); many of the latter have in fact left Iraq because of the danger to their staff. However, a few INGOs have made CAMHS a priority, for example the work of Diaconia in the north, and the assistance offered by the International Medical Corps in a rehabilitation programme for orphanages and the provision of mental health training for primary care doctors, mostly in central Iraq (AlObaidi et al, 2010a). The United Nations Children's Fund (UNICEF) has provided support to Iraqi children since 1952 in the areas of nutrition and immunisation, child protection and education and local training of primary care workers. Civil unrest and more specific threats to UNICEF staff have sometimes interrupted these efforts. Save the Children, partnered with Mercy Corps, has returned and since the end of 2008 has supported the psychosocial care of children in the Kurdistani northern part of Iraq.

Another challenge facing the delivery of CAMHS in Iraq is the shortage of human resources. None of the 100 or so psychiatrists in Iraq has formal training in child and adolescent mental health. According to the World Health Organization (2009), the only other mental health human resources include, nationally: 7 general practitioners practising mental health; 145 psychiatric nurses; 16 psychologists; and 25 social workers. In the majority of low- and middleincome countries, mental health awareness is lacking and low priority is given to mental health within general health planning (Murthy, 2008). In Iraq, the picture is even bleaker, as there are few CAMHS available in spite of the additional needs arising from the prolonged conflict and violence. With decreased awareness, the stigma associated with mental health problems is an obstacle compounded by widespread unconcern and a lack of scientific knowledge about mental health.

Mental healthcare in Iraq was a neglected area even before the 2003 war (Abed, 2003). The recent armed conflict has had a profound impact on children's physical and mental health. The problems facing Iraqi children have their roots in the decades immediately before 2003. For example, access to health services for children aged under 5 years is severely limited, especially in rural areas, and the mortality rate among those under 5 in Iraq is one of the highest in the Middle East (Awqati et al, 2009). There were no formal CAMHS before 
2003; however, some progress has occurred since then, including the implementation by the Iraqi Ministry of Health of a general mental health policy with an integrated CAMHS component. The current instability and shortage of resources are hindering these efforts. It is hard to compare the CAMHS between the two periods due to the lack of comparable data.

\section{Legislation and human rights}

The old Iraqi laws, proclaimed in the 1980s, continue to be valid but are difficult to navigate and are not in complete agreement with the United Nations Convention on the Rights of the Child and other international standards. A special commission has been charged with creating child protection policies, coordinating and monitoring the various projects under way in this area, and the adoption of legal resolutions related to child welfare. Child-care facilities, including juvenile welfare institutions, orphanages and centres for the care of mothers, children and people with disabilities were to be supervised and funded by the state. Establishing a separate child protection act may help to fill the gaps (AlObaidi et al, 2009).

\section{Needs assessment}

Major national surveys of child and adolescent mental health are lacking in Iraq. Resources for service monitoring and outcome effectiveness research are needed, as the present lack of statistical data and research findings makes it difficult to plan CAMHS. Nonetheless, several smaller studies have demonstrated increased rates of mental health problems among Iraqi children and adolescents, including post-traumatic stress disorder (PTSD) and attention-deficit hyperactivity disorder (ADHD) in the cities of Baghdad, Mosul and Nassiriya. One study in Mosul, for example, showed that $37 \%$ of children who were patients at a primary health facility complained of a mental disorder (Al-Jawadi \& AbdulRhman, 2007). PTSD was reported among $14 \%$ of children living in Baghdad and among 30\% of those living in Mosul (Razoki et al, 2006); 20\% of children were estimated to have PTSD among Iraqi Kurds in the north (Ahmad et al, 1998). In a clinical sample study conducted in Baghdad during 2005, anxiety disorders were diagnosed in $22 \%$ and behavioural problems in 18\% (AlObaidi et al, 2010b). In 2006 at Nassiriya, a city in southern Iraq, ADHD was found among $15 \%$ of schoolchildren (Sadik et al, 2008), and in Baghdad the prevalence of the disorder was estimated to be $5.9 \%$ during 1999 (AlObaidi \& Ali, 2009).

National professional population surveys of the mental health of children and adolescents that are culturally sensitive are needed to form a secure base for the establishment of child and adolescent mental health policy.

\section{Baselines for CAMHS in Iraq}

Much remains to be done to meet the mental health needs of children and adolescents in Iraq. A system of low-cost service delivery staffed by well-trained health professionals is required that focuses on child, family, school-based and community mental health. It is necessary to build a well trained workforce of health professionals within the primary health setting who have fundamental CAMHS skills and who are able to track progress the development of CAMHS and early-intervention services. Comprehensive, culturally sensitive CAMHS grounded in the existing local infrastructure should be developed by local professionals and evaluated for the effectiveness of their outcomes.

\section{References}

Abed, R. (2003) An update on mental health services in Iraq. Psychiatric Bulletin, 27, 461-462.

Ahmad, A., Mohammad, H. \& Ameen, N. (1998) A 26-month follow-up of posttraumatic stress symptoms in children after the Mass-Escape Tragedy in Iraqi Kurdistan. Nordic Journal of Psychiatry, 52, 357-366.

Al-Jawadi, A. A. \& Abdul-Rhman, S. (2007) Prevalence of childhood and early adolescence mental disorders among children attending primary health care centers in Mosul, Iraq: a cross-sectional study. BMC Public Health. Open-access article available at http://www.biomedcentral. com/1471-2458/7/274 (accessed November 2010).

AlObaidi, A.K. \& Ali, N. S. (2009) Attention-deficit/hyperactivity disorder among school children in Baghdad. Journal of the Canadian Academy of Child and Adolescent Psychiatry, 18, 4-5.

AlObaidi, A.K., Jeffrey, L. R., Scarth, L., et al (2009) Iraqi children's rights: building a system under fire. Medicine, Conflict and Survival, 25, 145-162.

AlObaidi, A.K., Budosan, B. \& Jeffrey, L. (2010a) Child and adolescent mental health in Iraq: current situation and scope for promotion of child and adolescent mental health policy. Intervention, 8, 40-51.

AlObaidi, A.K., Scarth, L. \& Dwivedi, K. N. (2010b) Mental disorder in children attending a child psychiatric clinic at the General Paediatric Hospital in Baghdad. Journal for International Mental Health Promotion, 12, 24-30.

Awqati, A. N., Ali, M. M., Al-Ward, J. N., et al (2009) Causes and differentials of childhood mortality in Iraq. BMC Pediatrics, 9. Available at http://www.biomedcentral.com/1471-243/9/40 (accessed November 2010).

Murthy, R. S. (2008) Mental health and psychosocial support in conflict situations in the Eastern Mediterranean Region. Intervention, 6, 239-242.

Razoki, A. H., Taha, I. K., Taib, N. I., et al (2006) Mental health of Iraqi children. Lancet, 368, 838-839.

Sadik, S., Al-Sayyad, H. W. \& Sadoon, A. (2008) Prevalence of attentiondeficit hyperactivity disorder among junior school children at Nassiriya City. New Iraqi Journal of Medicine, 4(3), 17-24.

World Health Organization (2009) Iraq Mental Health Survey 2006/7 Report. WHO.

\section{New College report}

College report CR163, Psychiatric Services for Children and Adolescents with Intellectual Disabilities, deals with those people falling between child and adolescent psychiatry and intellectual disability psychiatry services. It reviews the resources required for a psychiatric service for young people (under 18 years) and their families. Starting with an overview of the changing approaches to the psychiatric needs of this population, the nature of its disorders and the variety of interventions, it sets out the characteristics of a model service dealing with its structure, location, personnel and resources. The report is aimed at anyone involved in planning or helping to develop a psychiatric service for children and adolescents with intellectual disabilities. This report replaces CR123 (and formerly CR70). 